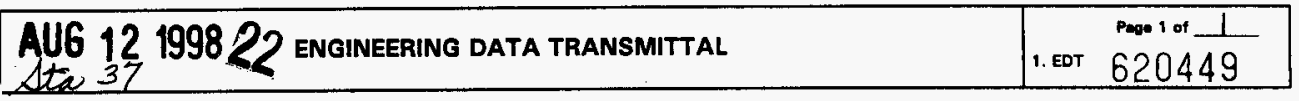

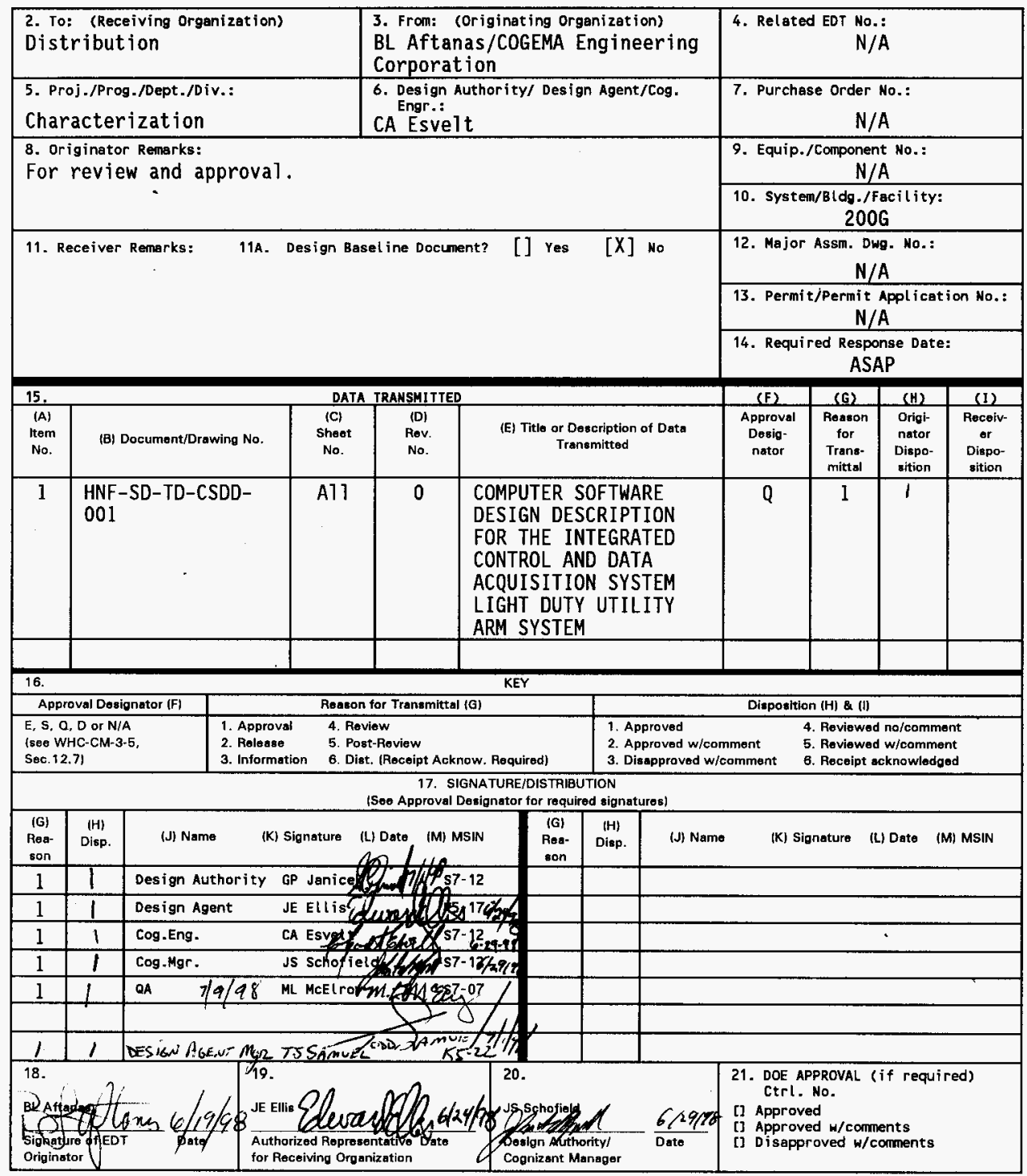

BD-7400-172-2 (05/96) GEF097 


\title{
COMPUTER SOFTWARE DESIGN DESCRIPTION FOR THE INTEGRATED CONTROL AND DATA ACQUISITION SYSTEM LDUA SYSTEM
}

\author{
BL Aftanas \\ COGEMA Engineering Corporation, Richland, WA 99352 \\ U.S. Department of Energy Contract DE-AC06-96RL13200 \\ EDT/ECN: 620449 \\ UC: 2070 \\ Org Code: 08E00 \\ Charge Code: $025 \mathrm{~K} 2 \mathrm{wo}_{12}-98$
Total Pages: \\ B\&R Code: EW3120074
}

Key Words: Light Duty Utility Arm, LDUA, software design description, SDD, CSDD, integrated control and data acquisition system

Abstract: This Computer Software Design Description (CSDD) provides the overview of the software design for all the software that is part of the integrated control and data acquisition system of the Light Duty Utility Arm System (LDUA). It describes the major software components and how they interface.

TRADEMARK DISCLAIMER. Reference herein to any specific commercial product, process, or service by trade name, trademark, manufacturer, or otherwise, does not necessarily constitute or imply its endorsement, reconmendation, or favoring by the United States Goverment or any agency thereof or its contractors or subcontractors.

Printed in the United states of America. To obtain copies of this document, contact: Document Control Services, P.0. Box 950, Mailstop H6-08, Richland WA 99352, Phone (509) 372-2420; Fax (509) 376-4989.
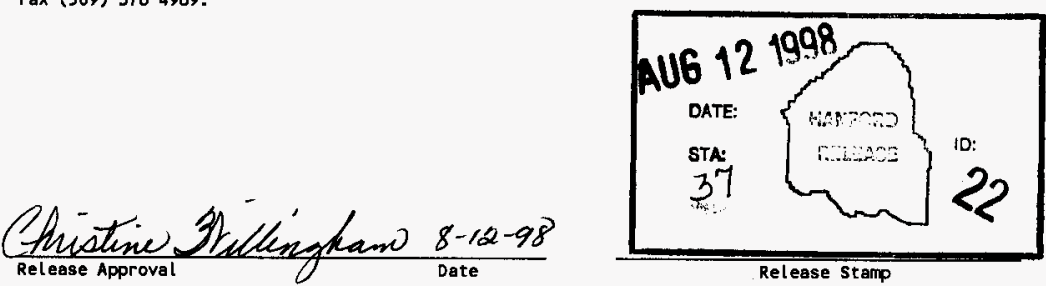

Release Stamp 


\section{COMPUTER SOFTWARE DESIGN DESCRIPTION FOR THE INTEGRATED CONTROL AND DATA ACQUISITION SYSTEM \\ LIGHT DUTY UTILITY ARM SYSTEM}

$$
\text { Rev } 0
$$

G. R. Kiebel

J. E. Ellis

December 13, 1996 
HNF-SD-TD-CSDD-001, Rev 0

Page ii

\section{COMPUTER SOFTWARE DESIGN DESCRIPTION FOR THE INTEGRATED CONTROL AND DATA ACQUISITION SYSTEM LIGHT DUTY UTILITY ARM SYSTEM}

TABLE OF CONTENTS

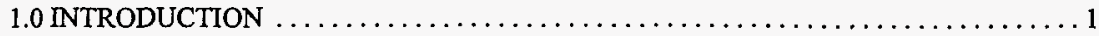

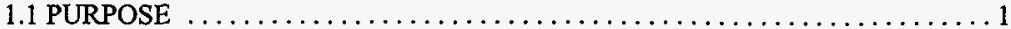

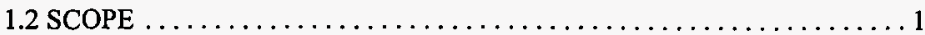

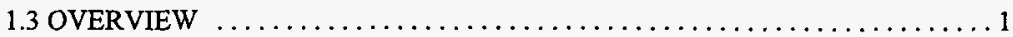

1.3.1 BACKGROUND OF APPLICATION $\ldots \ldots \ldots \ldots \ldots \ldots \ldots \ldots \ldots$

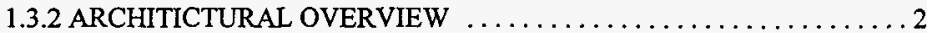

1.3.3 OVERVIEW OF HARDWARE DESIGN $\ldots \ldots \ldots \ldots \ldots \ldots \ldots \ldots$

1.3.4 OVERVIEW OF SOFTWARE DESIGN $\ldots \ldots \ldots \ldots \ldots \ldots \ldots \ldots \ldots$

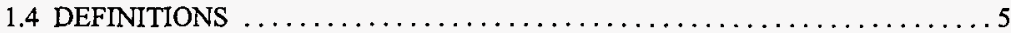

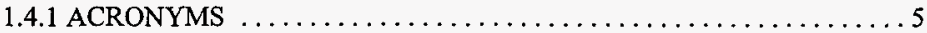

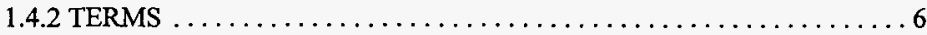

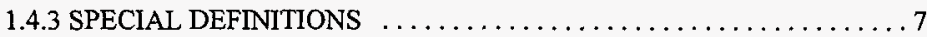

1.4.3.1 SOFTWARE CATEGORIES $\ldots \ldots \ldots \ldots \ldots \ldots \ldots \ldots \ldots$

1.5 OVERVIEW OF CSDD $\ldots \ldots \ldots \ldots \ldots \ldots \ldots \ldots \ldots \ldots \ldots \ldots \ldots \ldots$

2.0 DECOMPOSITION DESCRIPTION $\ldots \ldots \ldots \ldots \ldots \ldots \ldots \ldots \ldots \ldots$

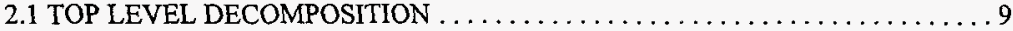

2.2 DATA ENTITY DECOMPOSITION $\ldots \ldots \ldots \ldots \ldots \ldots \ldots \ldots \ldots$

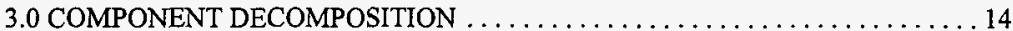

3.1 SUBSYSTEM CONTROLLER COMPONENT $\ldots \ldots \ldots \ldots \ldots \ldots \ldots \ldots \ldots$

3.1.1 Functional Description ............................. 14

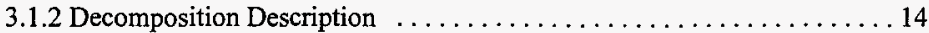

3.1.3 Dependency Description .............................. 14

3.1.4 Interface Description . . . . . . . . . . . . . . . . . . . . . . . . . . . . 15

3.1.5 Module Details .................................... 15

3.1.6 HMI Description . . . . . . . . . . . . . . . . . . . . . . . . 15

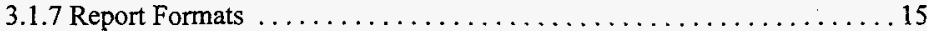

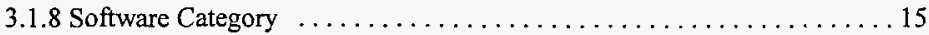

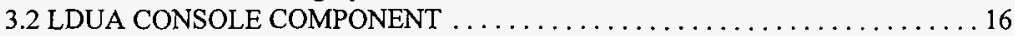

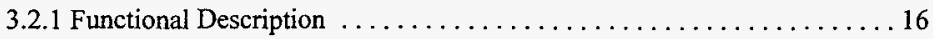




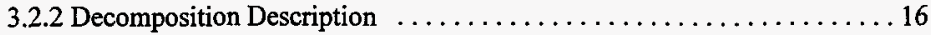

3.2.3 Dependency Description .............................. 16

3.2 .4 Interface Description . . . . . . . . . . . . . . . . . . . . . 16

3.2.5 Module Details . . . . . . . . . . . . . . . . . . . . . . . 16

3.2.6 HMI Description ................................. 17

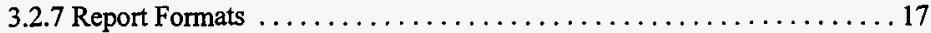

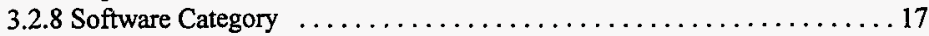

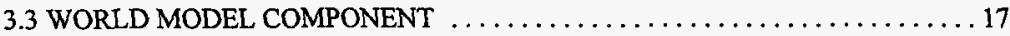

3.3.1 Functional Description . ........................... 17

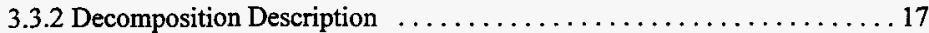

3.3.3 Dependency Description . . . . . . . . . . . . . . . . . . . . 18

3.3.4 Interface Description . . . . . . . . . . . . . . . . . . . . . . . 18

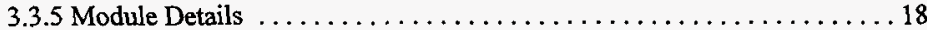

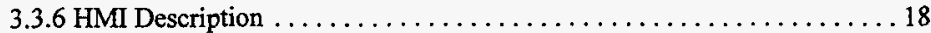

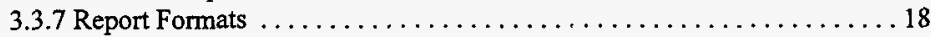

3.3.8 Software Category .................................. 19

3.4 LDUA ROBOT POSITION SERVER COMPONENT $\ldots \ldots \ldots \ldots \ldots \ldots \ldots \ldots$

3.4.1 Functional Description ........................... 19

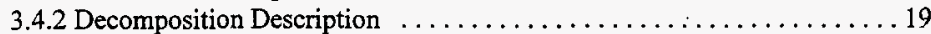

3.4.3 Dependency Description . . . . . . . . . . . . . . . . . . . . . 19

3.4.4 Interface Description . . . . . . . . . . . . . . . . . . . . . . . . 19

3.4.5 Module Details . . . . . . . . . . . . . . . . . . . . . . . . 20

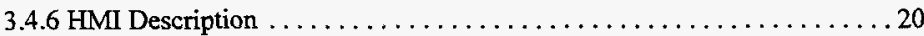

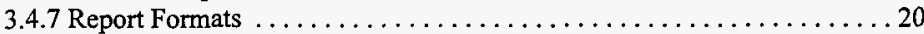

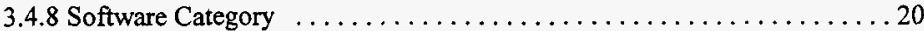

3.5 SUPERVISORY DATA ACQUISITION SYSTEM SERVER COMPONENT $\ldots 20$

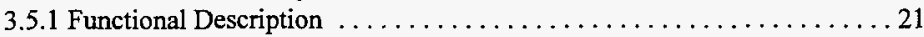

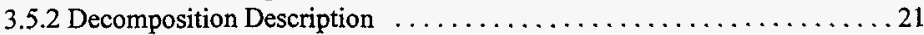

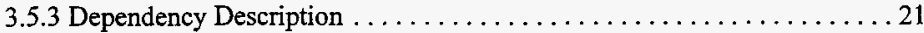

3.5.4 Interface Description . . . . . . . . . . . . . . . . . . . . . 21

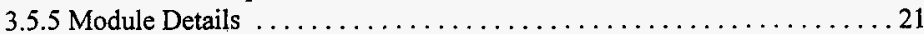

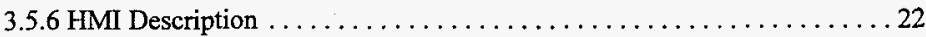

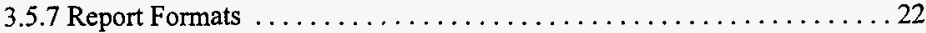

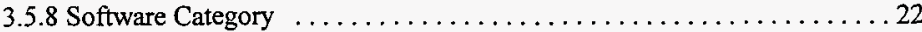

3.6 TOpSDAS USER INTERFACE COMPONENT $\ldots \ldots \ldots \ldots \ldots \ldots \ldots \ldots \ldots \ldots \ldots \ldots \ldots \ldots$

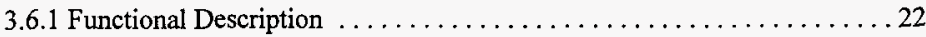

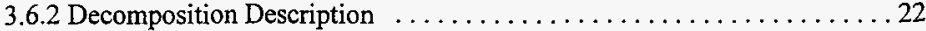

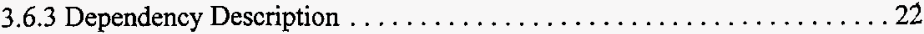

3.6.4 Interface Description . . . . . . . . . . . . . . . . . . . . . 23

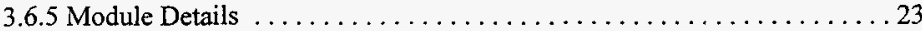

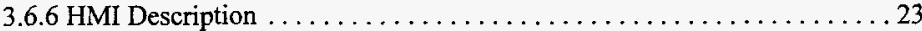

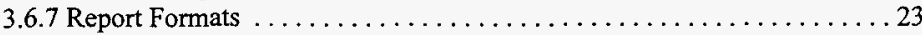




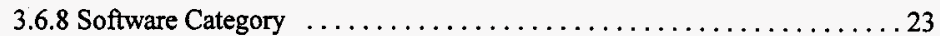

3.7 LDUA ROBOT POSITION CLIENT COMPONENT $\ldots \ldots \ldots \ldots \ldots \ldots \ldots 24$

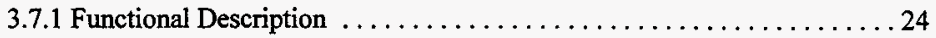

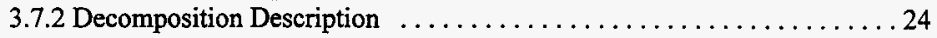

3.7.3 Dependency Description ........................... 24

3.7.4 Interface Description . . . . . . . . . . . . . . . . . . . . . . . 24

3.7.5 Module Details . . . . . . . . . . . . . . . . . . . . . . . 24

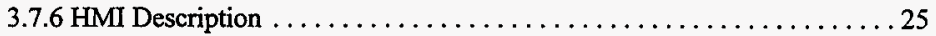

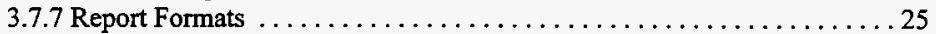

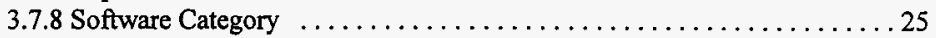

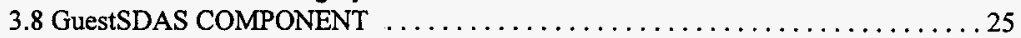

3.8.1 Functional Description ............................... 25

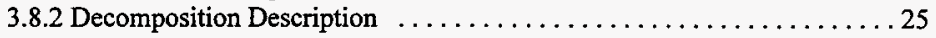

3.8.3 Dependency Description ............................... 25

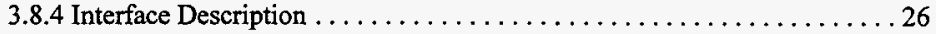

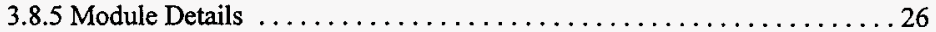

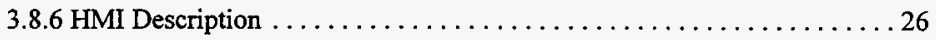

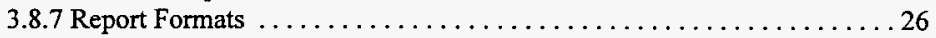

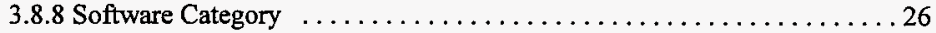

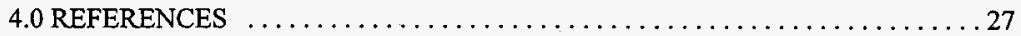


HNF-SD-TD-CSDD-001, Rev 0

Page v

\section{LIST OF FIGURES}

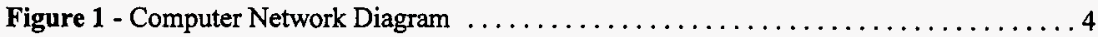

Figure 2 - Software Decomposition Context Diagram .................... 10

Figure 3 - Software Decomposition 0.0 Control Arm and Acquire Data $\ldots \ldots \ldots \ldots \ldots 11$

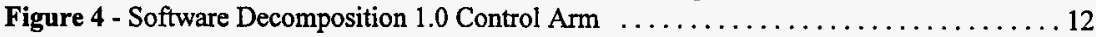

Figure 5 - Software Decomposition 2.0 Acquire Data $\ldots \ldots \ldots \ldots \ldots \ldots \ldots \ldots \ldots \ldots \ldots \ldots \ldots$ 
WHC-SD-TD-CSDD-001, Rev 0

Page 1

\subsection{INTRODUCTION}

\subsection{PURPOSE}

This Computer Software Design Description (CSDD) document provides the overview of the soffware design for all the software that is part of the integrated control and data acquisition system of the Light Duty Utility Arm System (LDUA). It describes the major software components and how they interface. It also references the documents that contain the detailed design description of the components.

\subsection{SCOPE}

This document describes a software design which satisfies requirements established in the LDUA software requirements documents (reference 3 ). It has been prepared in accordance with LDUA software development plan (reference 1). The CSDD is the primary software design deliverable required by the software development plan for the design phase of application software development.

\subsection{OVERVIEW}

\subsubsection{BACKGROUND OF APPLICATION}

The mission of the LDUA is to perform surveillance and characterization operations in support of the U.S. Department of Energy (DOE) goal of remediation of defense nuclear wastes currently stored in Hanford Underground Storage Tanks (USTs).

The Light Duty Utility Arm (LDUA) System has a multi-axis robotic manipulator arm with a 2.74 $\mathrm{m}(9 \mathrm{ft})$ reach and $34 \mathrm{~kg}(75 \mathrm{lb})$ payload that is mounted on the end of a $13.7 \mathrm{~m}(45 \mathrm{ft})$ positioning mast. It is designed to enter an UST through an available $30.5 \mathrm{~cm}(12 \mathrm{in}$.) riser.

A deployment vehicle carries the positioning equipment to insert the mast/manipulator arm into the riser, and a containment enclosure to control contamination when the mast/manipulator arm is in the tank or being transported from tank to tank. The system is controlled remotely from an operations and control trailer which is located outside the perimeter fence of the tank farm, up to 275 meters (900 feet) from the deployment vehicle. The LDUA System is also called the Arm/Deployment System, which will be referred to as "ARM" in the remainder of this document.

A set of interchangeable end effectors is carried on the end of the ARM. These end effectors provide a wide range of observation and measurement functions such as photographic and video 
WHC-SD-TD-CSDD-001, Rev 0

Page 2

inspection and recording, detailed surface mapping of the tank and surface of the waste, and insitu chemical analysis of the waste.

The ARM and each end effector has a subsystem controller that is responsible for controlling its basic function and which provides some amount of stand-alone operation. There is also a supervisory control and data acquisition system which operates at a level above all the subsystem controllers. This supervisory level integrates operation of the ARM and end effectors, and provides centralized data management.

The design of the LDUA control and data acquisition system is based on experience and technology gained from the Robotic Technology Development Program (RTDP) of the Office of Technology Development (OTD) of the U.S. Department of Energy (DOE).

The LDUA is being developed under the sponsorship of the Underground Storage Tank Integrated Demonstration (UST-ID) Program of the OTD. It is the goal of the UST-ID program is to demonstrate emerging technologies that are useful to characterization and remediation of USTs. Much of the work to date has been oriented toward research and toward producing prototypic systems for cold (nonradioactive) demonstrations. The LDUA system will be one of the first to be fully qualified for hot deployment.

The component parts of the LDUA are being supplied by a consortium of DOE sites and National Laboratories, some of them in partnership with commercial suppliers. Westinghouse Hanford Company (WHC), which operates the Hanford site under contract to the DOE, is providing the overall project coordination and system integration. The robot and its low-level control system are being supplied by a commercial vendor. Sandia National Laboratories is supplying the supervisory control and data acquisition system. End effectors are being supplied by Oak Ridge National Laboratory, Pacific Northwest Laboratory, Savanna River Technology Center, and Idaho National Engineering Laboratory.

The LDUA System will be implemented in successive stages, or missions: Mission one is mostly concerned with surveillance activities; mission two is involved with in-situ analysis of the waste; and mission three is concerned with depth penetration of the waste with possible small scale retrieval of samples. This document applies only to mission one, at present.

\subsubsection{ARCHITICTURAL OVERVIEW}

Much of the fundamental architecture of the LDUA control and data acquisition system is based on emerging technology, developed by the RTDP. This is an approach to the construction of control systems for complex robotic systems whereby sophisticated overall system performance is obtained by coordinating the operation of a collection of subsystems, each with complementary capabilities. Some subsystems operate as supervisors. Other subsystems must be capable of 
responding to directions from and reporting information to the supervisory level. Another key aspect of this approach is that the supervisors that provide the interface for basic operation of the robot to the user should be graphic and animated, and should be based upon a "World Model". The World Model is an accurate three dimensional description of the environment in which the robot operates, which is combined with an accurate kinematic model of the robot itself.

\subsubsection{OVERVIEW OF HARDWARE DESIGN}

Figure 1 shows a block diagram representing a high level overview of the integrated control and data acquisition system hardware. Figure 2 shows a block diagram of the computer environment that the software for the integrated control and data acquisition system runs in. It is a network of workstations and VME single board computers. The workstations run the Unix' operating system, and the VME CPUs run the VxWorks ${ }^{2}$ operating system.

\begin{tabular}{|c|c|c|c|}
\hline CPU & TYPE & $\begin{array}{l}\text { NODE } \\
\text { NAME }\end{array}$ & $\begin{array}{l}\text { OPERATING } \\
\text { SYSTEM } \\
\end{array}$ \\
\hline SCS Console & $\begin{array}{l}\text { Silicon Graphics Indigo }{ }^{3} 2 \\
\text { Extreme }\end{array}$ & fife & $\operatorname{IRIX}^{3} 5.2$ \\
\hline SDAS Console & Sun SparcStation ${ }^{4} 10$ & drum & Solaris ${ }^{4} 2.4$ \\
\hline Guest Console & Sun SparcStation ${ }^{4}$ IPX & harp & Solaris ${ }^{4} 2.4$ \\
\hline SDAS Server & Force $^{5}$ CPU30 (VME: 68030) & bass & VxWorks $^{2} 5.1 .1$ \\
\hline GISC CPU & Force ${ }^{5}$ CPU40 (VME: 68040) & vx3Gisc & VxWorks ${ }^{2} 5.1 .1$ \\
\hline LDUA Console & Sun SparcStation ${ }^{4} 5$ & ldua3 & Solaris ${ }^{4} 2.3$ \\
\hline Arm Level Controller & Force ${ }^{5}$ CPU40 (VME: 68040 ) & $v \times 3$ & VxWorks ${ }^{2} 5.2$ \\
\hline
\end{tabular}

\footnotetext{
${ }^{1}$ trademark of Novell-USG Inc.

${ }^{2}$ trademark of Wind River Systems Inc.

${ }^{3}$ trademark of Silicon Graphics, Inc.

${ }^{4}$ trademark of Sun Microsystems, Inc.
} 


\section{LDUA Computer Network Diagram}

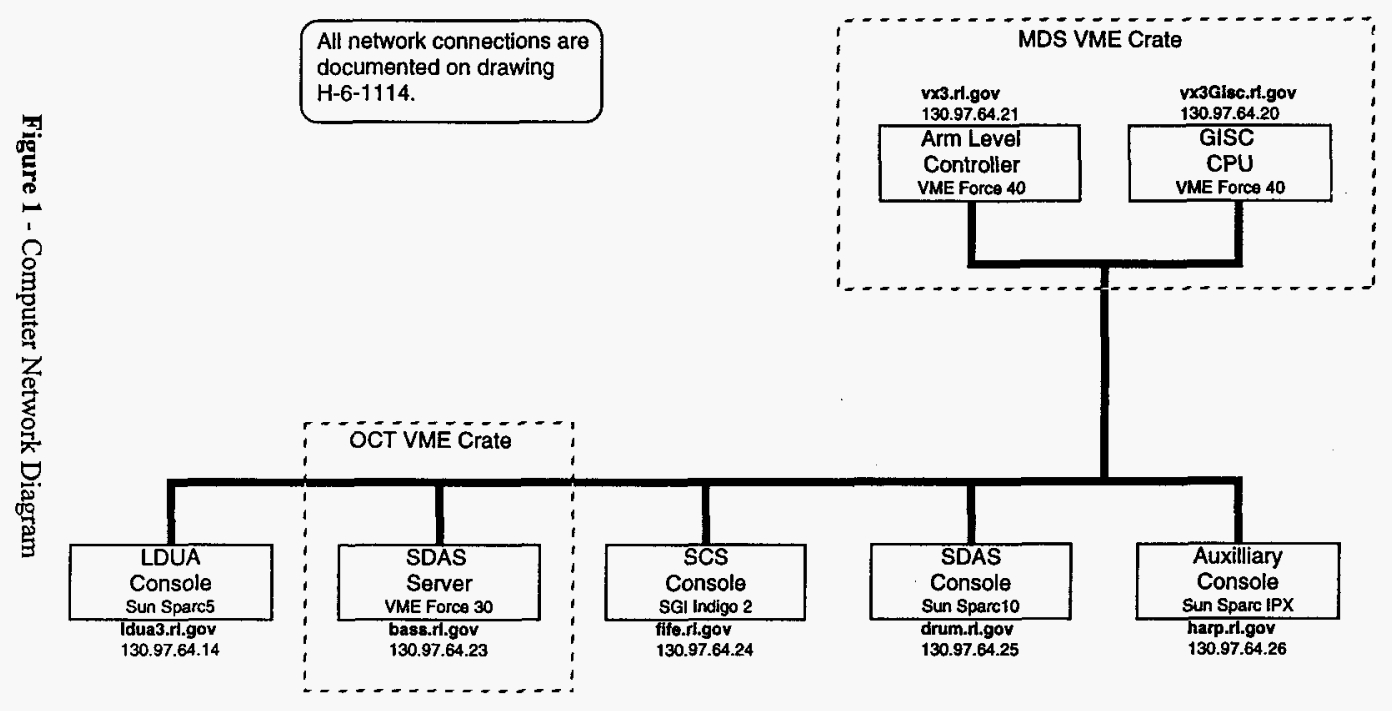




\subsubsection{OVERVIEW OF SOFTWARE DESIGN}

The integrated control and data acquisition system architecture has a supervisory level and a subsystem level. The supervisory level is divided into supervisory control and supervisory data acquisition. The supervisory level is concerned with centralization of control and data acquisition functions and with coordinated operation between subsystem. Supervisory operations are all conducted from the operations and control trailer. Subsystems include the mast/arm, the end effectors (some mounted on end of arm and some deployed by separate riser interface systems), and the Tank Riser Interface Containment (TRIC). Supervisory control provides a three dimensional graphic display as the primary user interface for controlling the LDUA arm. Supervisory data acquisition is able to acquire, process, display, and store data from the end effectors, and can tag this stored information with important operational data such as the identity of the operator, identity of the tank and riser of deployment, and position of the LDUA arm when it was taken. It also provides a means of displaying and recording video information from the end effectors and observational video cameras and can overlay titles and other selected information onto the video.

\subsection{DEFINITIONS}

\subsubsection{ACRONYMS}

ANSI American National Standards Institute

API Application Programming Interface

ARM Arm/Deployment System (synonym for LDUA System)

BOFFO Block Oriented File Format

CDR Conceptual Design Review

CSDD Computer Software Design Description

CSRS Computer Software Requirements Specification

DOE United States Department of Energy

EEES End Effector Exchange System

GENISAS General Interface for Supervisory and Subsystems 
GISC Generic Intelligent System Controller

GUI Graphic User Interface

HMI Human-Machine Interface

ISOE Intelligent System Operating Environment

INEL Idaho National Engineering Laboratory

LDUA Light Duty Utility Arm System

ORNL Oak Ridge National Laboratory

OTD DOE Office of Technology Development

PNL Pacific Northwest Laboratory

RIPE Robot Independent Programming Environment

RIPL Robot Independent Programming Language

RTDP Robotics Technology Development Program

SNL Sandia National Laboratories

TRIC Tank Riser Interface and Confinement

UST-ID Underground Storage Tank - Integrated Demonstration Program

UST Hanford Underground Storage Tank

$\mathrm{V} \& \mathrm{~V} \quad$ Verification and Validation

WHC Westinghouse Hanford Co.

\subsubsection{TERMS}

Application Software Is software which performs or supports the performance of the primary service or function of the LDUA system. Application software is the general term applied to the software covered by this CSRS document. 
Computer Soffware Media Is the different kinds of tapes, dises, etc. used by the computer for storing and retrieving software.

Computer Software Computer programs, procedures, and possibly associated documentation and data pertaining to the operation of a computer system.

Integrated system Is a term that refers to the complete control and data acquisition system, that is, the totality when all its various parts have come together.

Interactive refers to those applications where a user communicates with a computer program via a terminal, entering data and receiving responses from the computer.

On-line describes information or a function that is immediately available to the user from the computer, no preparatory work is required.

System Software - software which directly manages the physical computer resources on behalf of application software, and which supports it. For LDUA, this includes the computer operating system and its utility programs, data base management system, the language compiler.

\subsubsection{SPECIAL DEFINITIONS}

\subsubsection{SOFTWARE CATEGORIES}

The LDUA Software Development Plan (reference 1) established four categories for software components according to the method of implementing or obtaining the software component. The explanation of these categories is repeated here as a convenience to the reader because they are frequently referenced in this document:

A.Standard Commercial: This category of software is available off the shelf in the open market and is fully supported by the vendor.

B.Special Commercial: This category of software is supplied by a commercial vendor, but it is either not an off-the-shelf product or is not supported by the vendor.

C.Existing RTDP: This is software which has been developed under the RTDP; it typically embodies technology not yet available in marketplace, but which has been judged to be essential to LDUA.

D.Application Specific: This is software which will be developed new by Westinghouse Hanford Company or one of the other DOE contractors in the consortium. 


\subsection{OVERVIEW OF CSDD}

Section 2.0 of this document describes the top level decomposition of the LDUA software into its major components with key software interfaces shown.

Section 3.0 further describes each of the major components introduced in section 2.0. This further description includes: decomposition into modules; dependency among modules; interfaces between modules; and internal details of modules. The nature of the detail and method is appropriate to the nature of the component. As noted in the introduction to this document, it is at a preliminary draft stage and many of the details in this section have not been determined yet.

Section 4.0 lists the documents which are referenced by this document. 


\subsection{DECOMPOSITION DESCRIPTION}

\subsection{TOP LEVEL DECOMPOSITION}

Figure 3 shows the decomposition of the integrated LDUA software into its major components and the interfaces between them. These components are:

0.0 Control Arm and Acquire Data

1.0 Control Arm

1.1 Subsystem Controller

1.2 LDUA Console

1.3 World Model

1.4 LDUA Robot Position Server

1.5 Robot Interface

2.0 Acquire Data

2.1 Supervisory Data Acquisition System (SDAS) server

2.2 TopSDAS User Interface

2.3 LDUA Robot Position Client

2.4 GuestSDAS User Interface

\subsection{DATA ENTITY DECOMPOSITION}

At the current revision of this document, the Tank Farm Operations organization which is the customer for the LDUA has not determined any data quality objects. Currently, all data acquired is kept as video tapes, computer disc files, and written logs. If any future data quality object identifies a requirement for a more formal treatment, then an entity relation diagram and a database design will be done. 


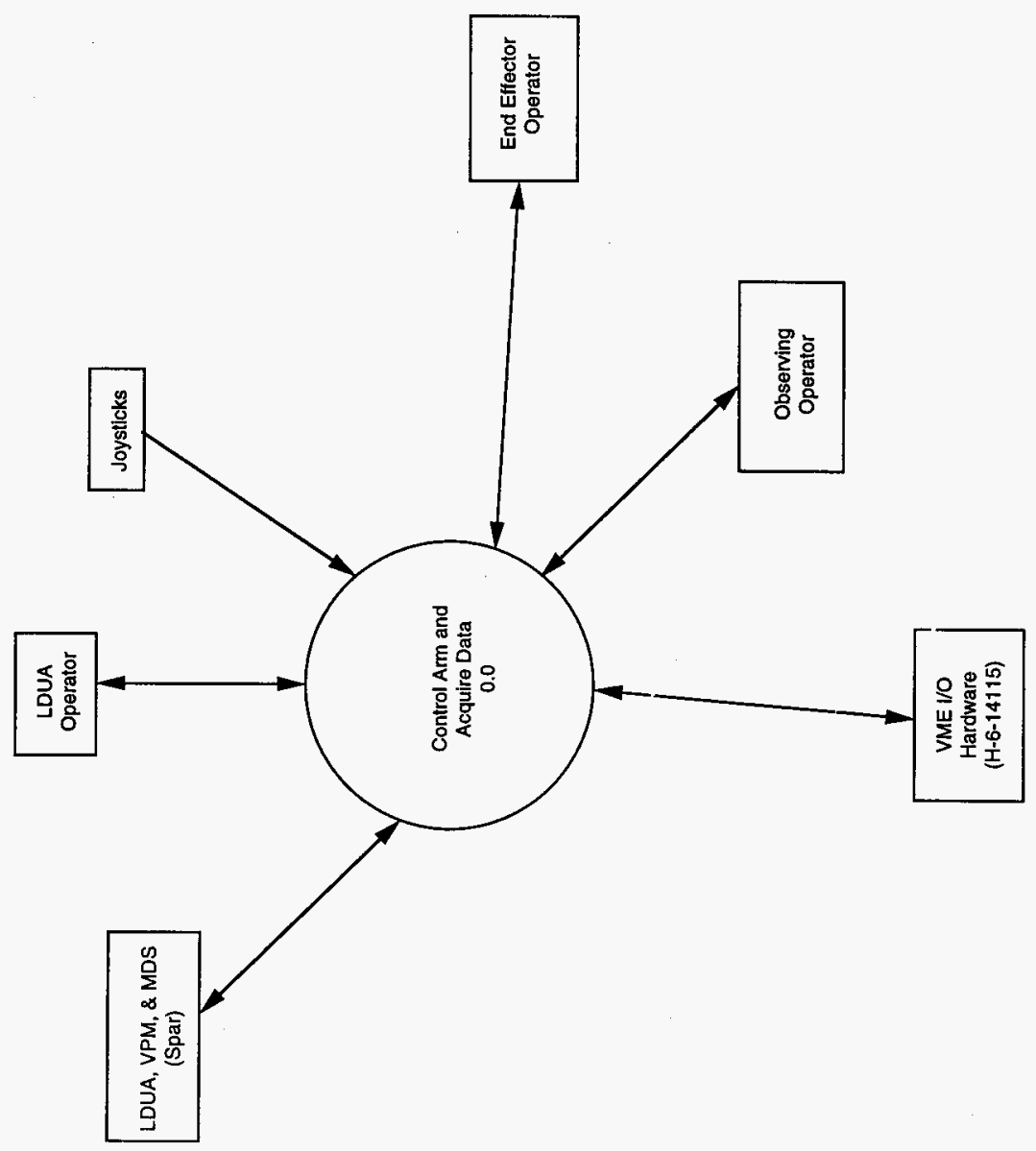

Figure 2 - Software Decomposition Context Diagram 


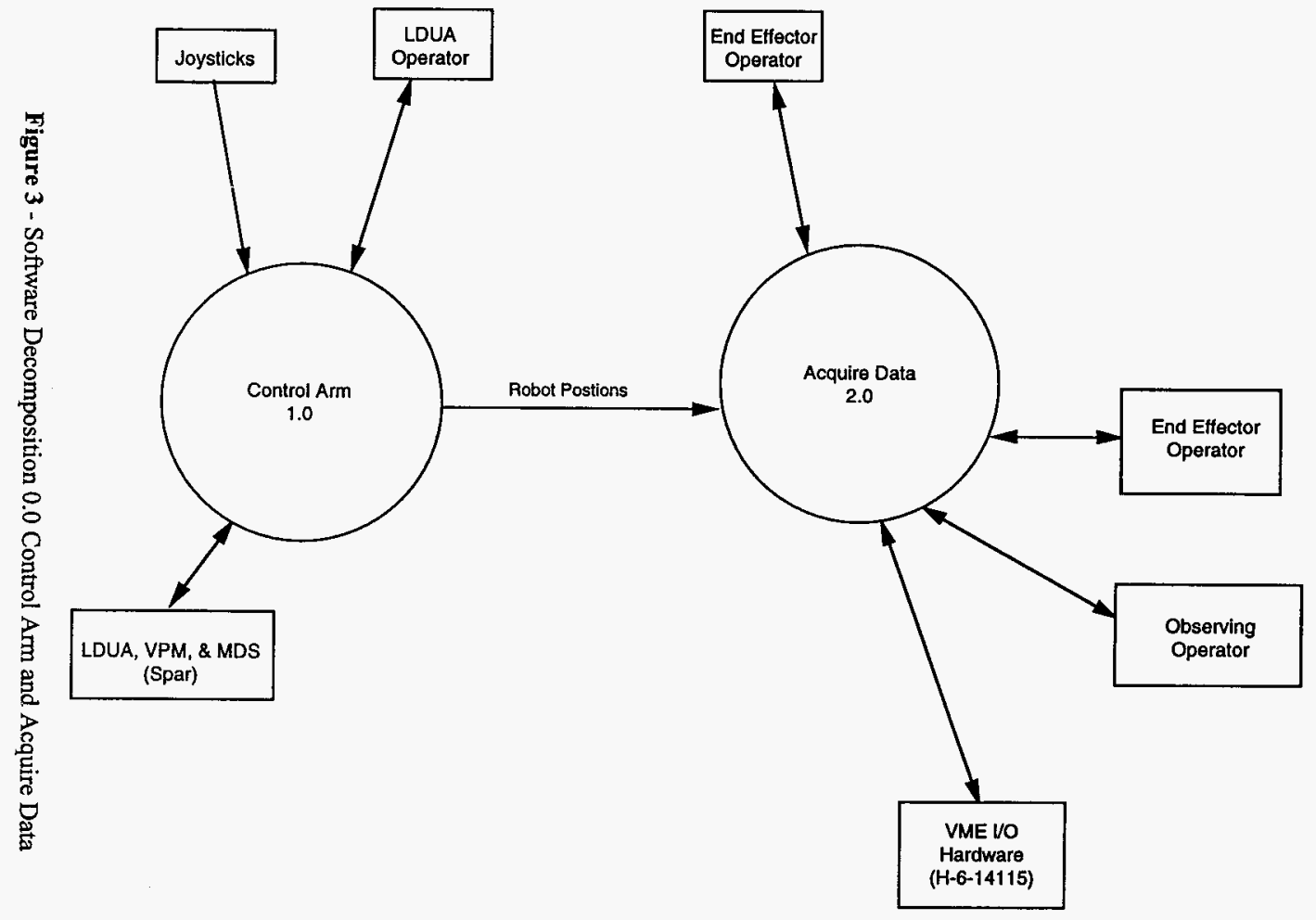

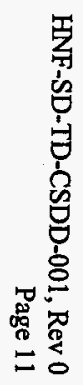


HNF-SD-TD-CSDD-001, Rev 0

Page 12

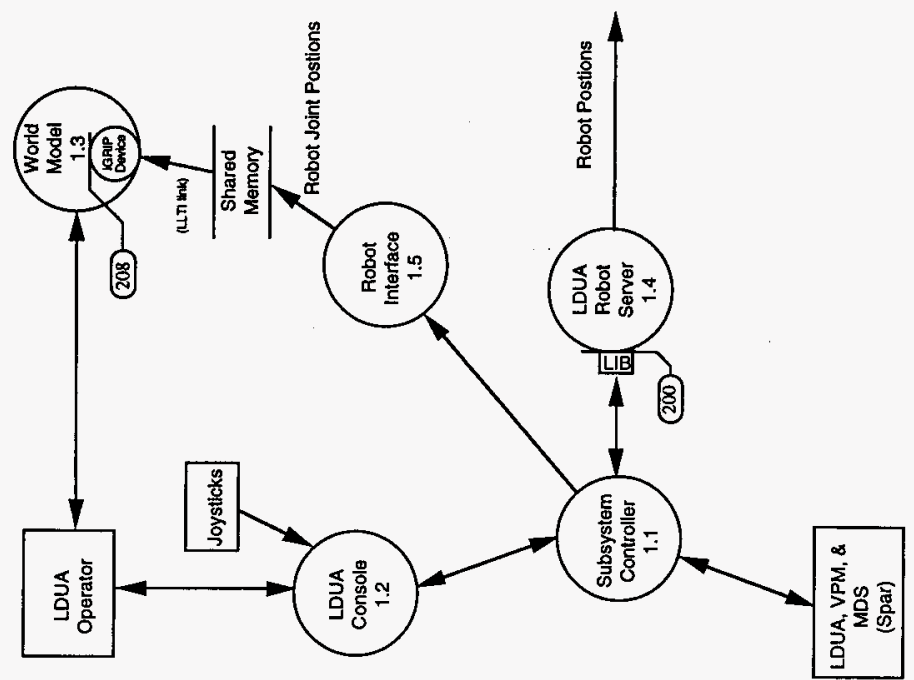

Figure 4 - Software Decomposition 1.0 Control Arm 


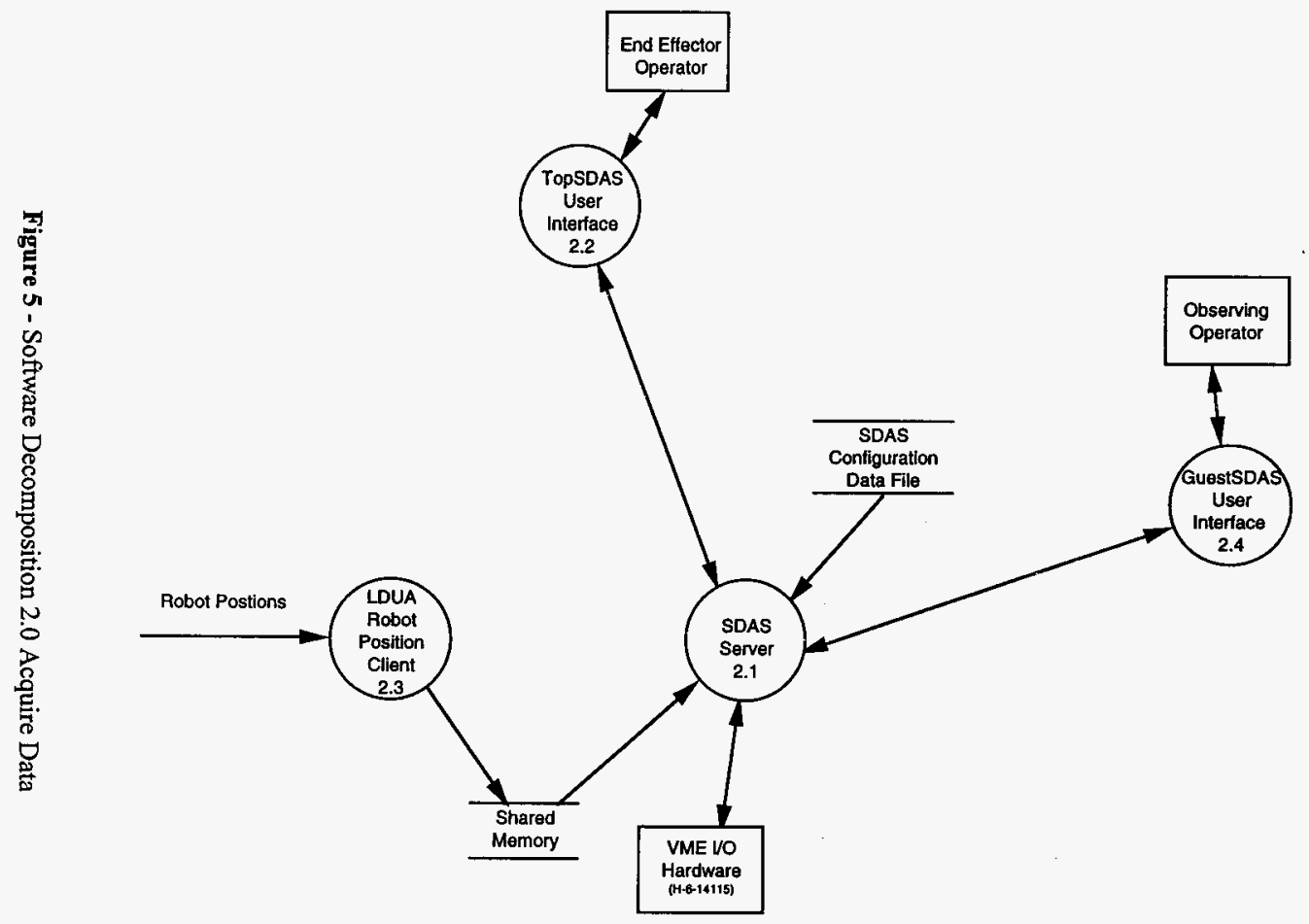

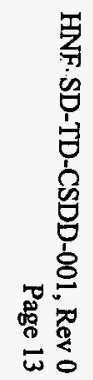




\subsection{COMPONENT DECOMPOSITION}

This section describes the top level modules introduced in section 2.0 , and their further decomposition.

\subsection{SUBSYSTEM CONTROLLER COMPONENT}

\subsubsection{Functional Description}

This component represents a portion of the Control System which is System 2400 . The Subsystem Controller provides the control logic for the automated and manual operation of the mast and arm and for the TRIC and its subsystems.

The Subsystem Controller provides control of each axis of the arm and the vertical motion of the deployment mast. In addition, coordinated world and tool frame motion is provided for both the arm and the mast. The mast and arm can be directed by teleoperation (human-in-the-loop) or by designation of a goal point or a path defined by a set of intermediate goal points. A simulation mode is provided whereby the motion of the mast and arm can be simulated with the joint drives inhibited. The Subsystem Controller is capable of following a trajectory that places the endeffector in contact with a surface that constrains the motion.

The Subsystem Controller also provides high-level (automatic) and low-level operation of certain TRIC subsystems (isolation valves, isolation door, and End Effector Exchange System).

\subsubsection{Decomposition Description}

The decomposition of this component is wholly within the scope of the supplier, Spar Aerospace, Ltd. Documentation is included in the Detail Design Review package in the Light Duty Utility Arm and Deployment System Software Design Description (reference 5).

\subsubsection{Dependency Description}

This component runs on the Arm Level Controller CPU (see section 1.3.3). 
HNF-SD-TD-CSDD-001, Rev 0

Page 15

\subsubsection{Interface Description}

This interface is between the Arm Level Controller (Spar) and the LDUA Robot Position Server (SNL). It provides an interface to the LDUA robot which is defined in terms of LDUA specific commands. It is defined as a set of ' $\mathrm{C}$ ' language function calls and supporting constants and data types which the Subsystem Controller provides and which the LDUA Robot Position Server can call. The specifications of the interface are given by the $\mathrm{C}$ language header file "Idua_api.h" (reference 5). Spar is responsible for this file and the Software that implements the functions defined in the interface. This software is in the form of a VxWorks library (".o" form) which is loaded into the GISC CPU and which communicates with the Arm Level Controller over the VME backplane.

All other interfaces with this component are wholly contained within the Spar scope of supply and are not detailed in this document.

\subsubsection{Module Details}

The design details of the modules which make up this component are wholly within the scope of the supplier, Spar Aerospace, Ltd. Documentation is included in the Detail Design Review package in the Light Duty Utility Arm and Deployment System Software Design Description (reference 5).

\subsubsection{HMI Description}

This component is not expected to have its direct interface to the end user.

\subsubsection{Report Formats}

This component is not expected to produce any formal reports, but it is expected to accumulate operating and error logs. Details are included in the Detail Design Review package in the Light Duty Utility Arm and Deployment System Software Design Description (reference 5).

\subsubsection{Software Category}

This component is category B, Special Commercial (see section 1.4.3.1) and is supplied by Spar Aerospace, Ltd. under contract to Westinghouse Hanford Company. It is governed by procurement specification (reference 2). 
HNF-SD-TD-CSDD-001, Rev 0

Page 16

\subsection{LDUA CONSOLE COMPONENT}

\subsubsection{Functional Description}

This component represents a portion of the Control System which is System 2400. The LDUA Console provides commands and displays to allow the operator to fully operate the deployment mast, arm, and on-board camera, and certain subsystems of the TRIC. It displays the status information and all the operating parameters provided in the Subsystem Controller, and provides commands for changing parameters.

\subsubsection{Decomposition Description}

The decomposition of this component is wholly within the scope of the supplier, Spar Aerospace, Ltd. Documentation is included in the Detail Design Review package in the Light Duty Utility Arm and Deployment System Software Design Description (reference 5).

\subsubsection{Dependency Description}

This component runs on the LDUA Console CPU (see section 1.3.3).

\subsubsection{Interface Description}

This interface is between the LDUA Console (Spar) and the World Model (WHC). This interface transmits regular updates of the joint angles from the LDUA Console via an IGRIP LLTI socket connection. This information is used to provide a three dimensional graphic simulation of the LDUA. Documentation is included in the Detail Design Review package in the Light Duty Utility Arm and Deployment System Software Design Description (reference 5).

All other interfaces with this component are wholly contained within the supplier's scope and are not detailed in this document.

\subsubsection{Module Details}

The design details of the modules which make up this component are wholly within the scope of the supplier, Spar Aerospace, Ltd. Documentation is included in the Detail Design Review 
package in the Light Duty Utility Arm and Deployment System Software Design Description (reference 5).

\subsubsection{HMI Description}

The design details of the human machine interface are wholly within the scope of the supplier, Spar Aerospace, Ltd. Documentation is included in the Detail Design Review package in the Light Duty Utility Arm and Deployment System Software Design Description (reference 5).

\subsubsection{Report Formats}

The design details of the reports are wholly within the scope of the supplier, Spar Aerospace, Ltd. Documentation is included in the Detail Design Review package in the Light Duty Utility Arm and Deployment System Software Design Description (reference 5).

\subsubsection{Software Category}

This component is category B, Special Commercial (see section 1.4.3.1) and is supplied by Spar Aerospace, Ltd. under contract to Westinghouse Hanford Company. It is governed by procurement specification (reference 2).

\subsection{WORLD MODEL، COMPONENT}

\subsubsection{Functional Description}

This component represents a portion of the Supervisory Control System which is System 4210 . The World Model Component provides a three dimensional, color graphic animated display of the mast/arm and tank environment as an auxiliary user interface for controlling the mast and arm, and provides path preview and collision avoidance checking. The requirements are included in the Detail Design Review package in the Computer Software Requirements Specification for the World Model (reference 4).

\subsubsection{Decomposition Description}

There is no decomposition of this component. The design consists of making one or several small IGRIP macros for each requirement in the Computer Software Requirements Specification for the World Model (reference 4) and connecting them to user buttons on a special User Menu. 
HNF-SD-TD-CSDD-001, Rev 0

Page 18

The User Menu is described in the SCADAS Operations and Maintenance Manual (reference 10).

\subsubsection{Dependency Description}

This component runs on the SCS Console (see section 1.3.3).

\subsubsection{Interface Description}

This interface is between the LDUA Console (Spar) and the World Model (WHC). This interface transmits regular updates of the joint angles from the LDUA Console via an IGRIP LLTI socket connection. This information is used to provide a three dimensional graphic simulation of the LDUA. Documentation is included in the Detail Design Review package in the Light Duty Utility Arm and Deployment System Software Design Description (reference 5).

All other interfaces with this component are wholly contained within the supplier's scope and are not detailed in this document.

\subsubsection{Module Details}

The design of this component is so simplistic that no module details for this component will be developed.

\subsubsection{HMI Description}

This component displays an animated model of the mast and arm that moves within an accurate representation of the tank environment. The animated model of the arm shall accurately show the actual position of the mast and arm and shall follow their motion in near-real time.

Specific display screen layouts are documented in the SCADAS Operations and Maintenance Manual (reference 10).

\subsubsection{Report Formats}

This component is not expected to produce any reports. 


\subsubsection{Software Category}

This component is category D, Application Specific (see section 1.4.3.1) and is supplied by Westinghouse Hanford Company.

\subsection{LDUA ROBOT POSITION SERVER COMPONENT}

\subsubsection{Functional Description}

This component represents a portion of the Supervisory Control System which is System 4210. This component provides a low-level software interface to the LDUA subsystem by translating from the robot independent (RIPE/RIPL) commands (reference 6) into LDUA specific commands. This lays a foundation for the future. It allows us to add advanced supervisory features in the future which are based on RIPE/RIPL.

\subsubsection{Decomposition Description}

The decomposition of this component is wholly within the scope of the supplier, Sandia National Laboratories. Documentation is included in the Detail Design Review package in "Software Design Document: LDUA Robot Position Client/Server" (reference 7).

\subsubsection{Dependency Description}

This component runs on the GISC CPU (see section 1.3.3).

\subsubsection{Interface Description}

This interface is between the Arm Level Controller (Spar) and the LDUA Robot Position Server (SNL). It provides an interface to the LDUA robot which is defined in terms of LDUA specific commands. It is defined as a set of ' $\mathrm{C}$ ' language function calls and supporting constants and data types which the Subsystem Controller provides and which the LDUA Robot Position Server can call. The specifications of the interface are given by the C language header file "ldua_api.h" (reference 5). Spar is responsible for this file and the Software that implements the functions defined in the interface. This software is in the form of a VxWorks library (".o" form) which is loaded into the GISC CPU and which communicates with the Arm Level Controller over the VME backplane. 
This interface is between the LDUA Robot Position Server (SNL) and the LDUA Robot Position Client (SNL). It provides an interface to the LDUA robot which is defined in terms of the Robot Independant Programming Language (RIPL) (reference 6). The LDUA Robot Position Client uses this interface to obtain the LDUA position information required by the Supervisory Data Acquisition System. This interface will be used to add advanced supervisory features in the future which are based on RIPL.

All other interfaces with this component are wholly contained within the supplier's scope and are nor detailed in this document.

\subsubsection{Module Details}

The details of the sub-components of this component are documented in the Detail Design Review package in "Software Design Document: LDUA Robot Position Client/Server" (reference 7).

\subsubsection{HMI Description}

This component is not expected have a direct interface with the end user, but will have a low level user interface for testing and diagnostics.

\subsubsection{Report Formats}

This component is not expected to produce any reports.

\subsubsection{Software Category}

This component is supplied by Sandia National Laboratories and is category D, Application Specific (see section 1.4.3.1). However, some supporting subcomponents are category C, Existing RTDP.

\subsection{SUPERVISORY DATA ACQUISITION SYSTEM SERVER COMPONENT}


HNF-SD-TD-CSDD-001, Rev 0

Page 21

\subsubsection{Functional Description}

This component provides the acquires data in real-time and stores it in a database simultaniously accessable to multiple operators. It also provides any hardware dependent interface as hardware specific drivers.

\subsubsection{Decomposition Description}

The decomposition of this component is wholly within the scope of the supplier, Sandia National Laboratories. Documentation is included in the Detail Design Review package in "Supervisory Data Acquisition System Software Design Document" (reference 8).

\subsubsection{Dependency Description}

This component has two sub-components, the SDAS server and the Client Interface. The SDAS server runs on the SDAS Server CPU. The Client Interface runs on whatever machine supports a client. The two clients in this system are the TopSDAS User Interface, which runs on the SDAS Console, and the GuestSDAS User Interface, which runs on the Guest Console (see section 1.3.3).

\subsubsection{Interface Description}

The interface between the SDAS Server Client Interface sub-component and the User Interface programs is implemented as LabVIEW library virtual instruments. These are documented in the "SDAS Programmer's Manual" (reference 9).

All other interfaces with this component are wholly contained within the supplier's scope and are not detailed in this document.

\subsubsection{Module Details}

The details of the sub-components of this component are documented in the Detail Design Review package in "Supervisory Data Acquisition System Software Design Document" (reference 8). 


\subsubsection{HMI Description}

This component does not have a direct interface with the end user.

\subsubsection{Report Formats}

This component does not generate any reports.

\subsubsection{Software Category}

This component is supplied by Sandia National Laboratories and is category D, Application Specific (see section 1.4.3.1).

\subsection{TopSDAS USER INTERFACE COMPONENT}

\subsubsection{Functional Description}

This component represents the primary user interface to the Supervisory Data Acquisition System which is System 4220. The TopSDAS User Interface processes data, displays data, and controls the end effectors and the Video Display and Recording System (System 4230).

\subsubsection{Decomposition Description}

This component is implemented as LabVIEW virtual instruments. The structure of the program is readily visible in the LabVIEW visual editor. The design of the program is the "pancake" model, which has a top level dispatcher that simply calls one of the many functional modules. Structure below the first level is left up to the discretion of the programmer.

\subsubsection{Dependency Description}

This component will run on the SDAS Console (see section 1.3.3). 


\subsubsection{Interface Description}

The interface between the SDAS Server Client Interface sub-component and the User Interface programs is implemented as LabVIEW library virtual instruments. These are documented in the "SDAS Programmer's Manual" (reference 9).

All other interfaces with this component are wholly contained within the supplier's scope and are not detailed in this document.

\subsubsection{Module Details}

There are no further details of the sub-components of this component. The function of each control panel is documented in the SCADAS Operations and Maintenance Manual (reference $10)$.

\subsubsection{HMI Description}

The user interface for this component is documented in the SCADAS Operations and Maintenance Manual (reference 10).

\subsubsection{Report Formats}

This component does not produce any reports.

\subsubsection{Software Category}

This component is supplied by Westinghouse Hanford Company and is category D, Application Specific (see section 1.4.3.1). However, it is based on a commercial product, LabVIEW ${ }^{5}$ which is category $\mathrm{A}$, Standard Commercial.

${ }^{5}$ trademark of National Instruments 


\subsection{LDUA ROBOT POSITION CLIENT COMPONENT}

\subsubsection{Functional Description}

This component represents a portion of the Supervisory Control System which is System 4210 . This component takes mast/arm position information from the LDUA Robot Position Server and makes it available to Supervisory Data Acquisition System in a form which is more accessible to it.

\subsubsection{Decomposition Description}

The decomposition of this component is wholly within the scope of the supplier, Sandia National Laboratories. Documentation is included in the Detail Design Review package in "Software Design Document: LDUA Robot Position Client/Server" (reference 7).

\subsubsection{Dependency Description}

This component runs on the SDAS Server CPU (see section 1.3.3).

\subsubsection{Interface Description}

This interface is between the LDUA Robot Position Server (SNL) and the LDUA Robot Position Client (SNL). It provides an interface to the LDUA robot which is defined in terms of the Robot Independant Programming Language (RIPL) (references 6). The LDUA Robot Position Client uses this interface to obtain the LDUA position information required by the Supervisory Data Acquisition System.

All other interfaces with this component are wholly contained within the supplier's scope and are not detailed in this document.

\subsubsection{Module Details}

The details of the sub-components of this component are documented in the Detail Design Review package in "Software Design Document: LDUA Robot Position Client/Server" (reference 7). 
HNF-SD-TD-CSDD-001, Rev 0

Page 25

\subsubsection{HMI Description}

This component does not have a direct interface with the user.

\subsubsection{Report Formats}

This component does not produce any reports.

\subsubsection{Software Category}

This component, supplied by Sandia National Laboratories, is category D, Application Specific (see section 1.4.3.1).

\subsection{GuestSDAS COMPONENT}

\subsubsection{Functional Description}

This component represents a secondary user interface to the Supervisory Data Acquisition System which is System 4220 . The GuestSDAS User Interface processes data, displays data, and controls the guest observer portion of the Video Display and Recording System (System 4230).

\subsubsection{Decomposition Description}

This component is implemented as LabVIEW virtual instruments. The structure of the program is readily visible in the LabVIEW visual editor. The design of the program is the "pancake" model, which has a top level dispatcher that simply calls one of the many functional modules. Structure below the first level is left up to the discretion of the programmer.

\subsubsection{Dependency Description}

This component will run on the Guest Console (see section 1.3.3). 
HNF-SD-TD-CSDD-001, Rev 0

Page 26

\subsubsection{Interface Description}

The interface between the SDAS Server Client Interface sub-component and the User Interface programs is implemented as LabVIEW library virtual instruments. These are documented in the "SDAS Programmer's Manual" (reference 9).

All other interfaces with this component are wholly contained within the supplier's scope and are not detailed in this document.

\subsubsection{Module Details}

There are no further details of the sub-components of this component. The function of each control panel is documented in the SCADAS Operations and Maintenance Manual (reference $10)$.

\subsubsection{HMI Description}

The user interface for this component is documented in the SCADAS Operations and Maintenance Manual (reference 10).

\subsubsection{Report Formats}

This component does not produce any reports.

\subsubsection{Software Category}

This component is supplied by Westinghouse Hanford Company and is category D, Application Specific (see section 1.4.3.1). However, it is based on a commercial product, LabVIEW which is category A, Standard Commercial.

${ }^{6}$ trademark of National Instruments 
WHC-SD-TD-CSDD-001, Rev 0

Page 27

\subsection{REFERENCES}

1. WHC-SD-TD-SDP-001, LDUA Software Development Plan, Westinghouse Hanford Co., Richland, Washington, September 1989.

2. WHC-S-124, Specification For The Light Duty Utility Arm and Deployment System. Westinghouse Hanford Co., Richland, Washington, September 1989.

3. WHC-SD-TD-CSRS-001, Computer Software Requirements Specification For The Integrated Control And Data Acquisition System Light Duty Utility Arm System, Westinghouse Hanford Co., Richland, Washington, December 1995.

4. WHC-SD-TD-CSRS-002, Computer Software Requirements Specification For The World Model Light Duty Utility Arm System, Westinghouse Hanford Co., Richland, Washington, January 1996.

5. SPAR-LDUA-SW-018, Light Duty Utility Arm and Deployment System Software Design Description, Spar Aerospace Limited, Brampton, Ontario, Canada, Draft A, September 1994.

6. RIPE/RIPL Reference Manual, Sandia National Laboratories, Albuquerque, New Mexico, Version 3.0, 1994.

7. SNL-LDUA-96-003, Software Design Document: LDUA Robot Position Client/Server, Sandia National Laboratories, Albuquerque, New Mexico, Version 1.0, August 1996.

8. SNL-LDUA-96-014, Supervisory Data Acquisition System Software Design Document, Sandia National Laboratories, Albuquerque, New Mexico,, Version 1.0, July 1996.

9. SNL-LDUA-96-006, Supervisory Data Acquisition System: Programmer's Manual, Sandia National Laboratories, Albuquerque, New Mexico,, Version 1.0, July 1996.

10. WHC-SD-TD-OMM-001, Operation and Maintenance Manual for the Ldua Supervisory Control and Data Acquisition System (Ldua System 4200)And Control Network (Ldua System 4400), Westinghouse Hanford Co., Richland, Washington, July 1998. 